UCRL-ID-145113

\title{
Inductively Coupled Plasma Mass Spectrometry Uranium Error Propagation
}

\author{
D. P. Hickman, S. C. Maclean, D. Shepley, R. K. Shah
}

\section{July 2001}

U.S. Department of Energy

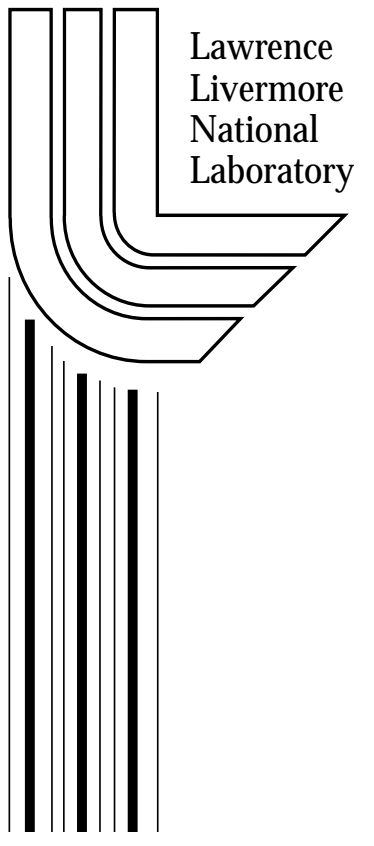




\section{DISCLAIMER}

This document was prepared as an account of work sponsored by an agency of the United States Government. N either the United States Government nor the University of California nor any of their employees, makes any warranty, express or implied, or assumes any legal liability or responsibility for the accuracy, completeness, or usefulness of any information, apparatus, product, or process disclosed, or represents that its use would not infringe privately owned rights. Reference herein to any specific commercial product, process, or service by trade name, trademark, manufacturer, or otherwise, does not necessarily constitute or imply its endorsement, recommendation, or favoring by the United States Government or the University of California. The views and opinions of authors expressed herein do not necessarily state or reflect those of the United States Government or the University of California, and shall not be used for advertising or product endorsement purposes.

This work was performed under the auspices of the U. S. Department of Energy by the University of California, Lawrence Livermore National Laboratory under Contract No. W-7405-Eng-48.

This report has been reproduced directly from the best available copy.

A vailable to $D O E$ and DOE contractors from the Office of Scientific and Technical Information

P.O. Box 62, Oak Ridge, TN 37831

Prices available from (423) 576-8401 http:/ / apollo.osti.gov/ bridge/

A vailable to the public from the National Technical Information Service

U.S. Department of Commerce 5285 Port Royal Rd., Springfield, VA 22161 http:/ / www.ntis.gov/

OR Lawrence Livermore N ational Laboratory Technical Information Department's Digital Library http:/ / www.Ilnl.gov/ tid/ Library.html 


\section{Introduction}

The Hazards Control Department at Lawrence Livermore National Laboratory (LLNL) uses Inductively Coupled Plasma Mass Spectrometer (ICP/MS) technology to analyze uranium in urine. The ICP/MS used by the Hazards Control Department is a PerkinElmer Elan 6000 ICP/MS. The Department of Energy Laboratory Accreditation Program requires that the total error be assessed for bioassay measurements. A previous evaluation of the errors associated with the ICP/MS measurement of uranium demonstrated a $\pm 9.6 \%$ error in the range of 0.01 to $0.02 \mu \mathrm{g} / \mathrm{l}$. However, the propagation of total error for concentrations above and below this level have heretofore been undetermined. This document is an evaluation of the errors associated with the current LLNL ICP/MS method for a more expanded range of uranium concentrations.

\section{Method}

Initial estimates of the variance for various uranium concentrations were determined using previous and concurrent QC samples. The variance was determined for ten ranges of spike levels. Based on these initial estimates of error, the number of samples necessary to establish the error within the spike range was determined using:

$$
n=\frac{4 \sigma^{2}}{L^{2}}
$$

where: $\mathrm{n}=$ the number of samples

$\sigma^{2}=$ the estimated variance

$\mathrm{L}=$ is the allowable error

Samples were prepared using a blank urine matrix and processed by the standard analysis method (HCL-I-3020). A 1-liter urine sample with low uranium content was acidified with nitric acid for use in this study. Aliquots were used to make blanks and NIST traceable spiked solutions. The analysis method (HCL-I-3020) uses nitric acid combined with a microwave digestion. The method also uses Uranium-233 as an internal tracer that adjusts the ICP/MS result due to degraded response during the readout process of a batch of samples. Each batch of samples contains a blank and NIST traceable uranium spikes that are used to assure the quality of the batch analysis. The current detection level is documented to be $0.002 \mathrm{ug} / \mathrm{l}$ with a reporting level of $0.01 \mathrm{ug} / \mathrm{l}$. The dosimetric action level has been established as $0.05 \mathrm{ug} / \mathrm{l}$.

An initial evaluation of the error associated with each measurement used the difference of the measured concentration minus the known concentration. This evaluation was used to empirically determine if any of the data appeared to deviate from an expected response of decreasing error as uranium concentrations increase. The standard deviation was calculated for each set of the ten spike levels. The standard deviation was calculated for each of the ten uranium standard concentrations. The fractional error was then determined for each known concentration by dividing the standard error by the known concentration. A non-linear fit using an exponential model was then performed using the 
fractional error and known uranium concentration to determine the functional relationship between these two variables.

\section{Results}

Results of the analysis of blanks and known concentrations are provided in Table 1. Based on an analysis of 10 replicate blanks, the known background concentration of uranium was determined to be $0.0046 \mathrm{ug} / \mathrm{l}$. The known uranium concentration additions were then added to the blank concentration to establish an expected concentration. This expected known concentration was established as the 'known' uranium concentration.

The percent difference between the measured and known concentration as a function of the uranium concentration can be observed in Figure 1. This difference reduced rapidly as the concentration increased from 'blank' levels to levels where the uranium can be reliably reported. After approximately $0.02 \mathrm{ug} / \mathrm{l}$ the error tends to remain fairly constant. It is noted that there is a consistent bias in the differences of approximately $+5 \%$. This bias may indicate a slight residual effect or an addition of uranium in the analysis process.

The percent error at 1 standard deviation for the ten different spike levels is illustrated in Figure 2. After $0.02 \mathrm{ug} / \mathrm{l}$ the errors tended to remain below $2 \%$. Therefore in constructing an exponential model, a lower boundary for the error was establish at $2 \%$. Modifications of this value did not improve the fit of the data to the model. The model and visual fit of the model can also be observed in Figure 2. The correlation statistic for the non-linear fit was better than 0.99 . 
Table 1. Results of uranium error study

\begin{tabular}{|c|c|c|c|c|}
\hline \multirow[b]{2}{*}{ Sample } & \multirow[b]{2}{*}{ Repl.\# } & \multicolumn{3}{|c|}{${ }^{238} \mathrm{U}$ Concentration, $\mu \mathrm{g} / \mathrm{L}$} \\
\hline & & Added & Total Expected & Measured \\
\hline Blank & 1 & 0 & $N / A$ & 0.0044 \\
\hline Blank & 2 & 0 & $\mathrm{~N} / \mathrm{A}$ & 0.0051 \\
\hline Blank & 3 & 0 & $\mathrm{~N} / \mathrm{A}$ & 0.0046 \\
\hline Blank & 4 & 0 & $\mathrm{~N} / \mathrm{A}$ & 0.0045 \\
\hline Blank & 5 & 0 & $\mathrm{~N} / \mathrm{A}$ & 0.0058 \\
\hline Blank & 6 & 0 & $\mathrm{~N} / \mathrm{A}$ & 0.0046 \\
\hline Blank & 7 & 0 & $\mathrm{~N} / \mathrm{A}$ & 0.0044 \\
\hline Blank & 8 & 0 & $\mathrm{~N} / \mathrm{A}$ & 0.0046 \\
\hline Blank & 9 & 0 & $\mathrm{~N} / \mathrm{A}$ & 0.0040 \\
\hline Blank & 10 & 0 & $\mathrm{~N} / \mathrm{A}$ & 0.0042 \\
\hline Blank+2 & 1 & 0.002 & 0.0066 & 0.0086 \\
\hline Blank+2 & 2 & 0.002 & 0.0066 & 0.0071 \\
\hline Blank+2 & 3 & 0.002 & 0.0066 & 0.0064 \\
\hline Blank +2 & 4 & 0.002 & 0.0066 & 0.0057 \\
\hline Blank+2 & 5 & 0.002 & 0.0066 & 0.0060 \\
\hline Blank+2 & 6 & 0.002 & 0.0066 & 0.0082 \\
\hline Blank +2 & 7 & 0.002 & 0.0066 & 0.0080 \\
\hline Blank+3 & 1 & 0.003 & 0.0076 & 0.0074 \\
\hline Blank+3 & 2 & 0.003 & 0.0076 & 0.0072 \\
\hline Blank+3 & 3 & 0.003 & 0.0076 & 0.0068 \\
\hline Blank +3 & 4 & 0.003 & 0.0076 & 0.0068 \\
\hline Blank +3 & 5 & 0.003 & 0.0076 & 0.0085 \\
\hline Blank+4 & 1 & 0.004 & 0.0086 & 0.0080 \\
\hline Blank+4 & 2 & 0.004 & 0.0086 & 0.0082 \\
\hline Blank+4 & 3 & 0.004 & 0.0086 & 0.0088 \\
\hline Blank +10 & 1 & 0.010 & 0.0146 & 0.0146 \\
\hline Blank+10 & 2 & 0.010 & 0.0146 & 0.0141 \\
\hline Blank+20 & 1 & 0.020 & 0.0246 & 0.0239 \\
\hline Blank+20 & 2 & 0.020 & 0.0246 & 0.0230 \\
\hline Blank+30 & 1 & 0.030 & 0.0346 & 0.0361 \\
\hline Blank+30 & 2 & 0.030 & 0.0346 & 0.0360 \\
\hline Blank+50 & 1 & 0.050 & 0.0546 & 0.0541 \\
\hline Blank +50 & 2 & 0.050 & 0.0546 & 0.0551 \\
\hline Blank+250 & 1 & 0.250 & 0.2546 & 0.2704 \\
\hline Blank +250 & 2 & 0.250 & 0.2546 & 0.2682 \\
\hline Blank+1000 & 1 & 1.000 & 1.005 & 1.0535 \\
\hline Blank +1000 & 2 & 1.000 & 1.005 & 1.0564 \\
\hline Blank+2000 & 1 & 2.000 & 2.005 & 2.1005 \\
\hline Blank+2000 & 2 & 2.000 & 2.005 & 2.0367 \\
\hline
\end{tabular}


Figure 1. Difference of the measured to known uranium concentration measurement as a function of known uranium concentration.

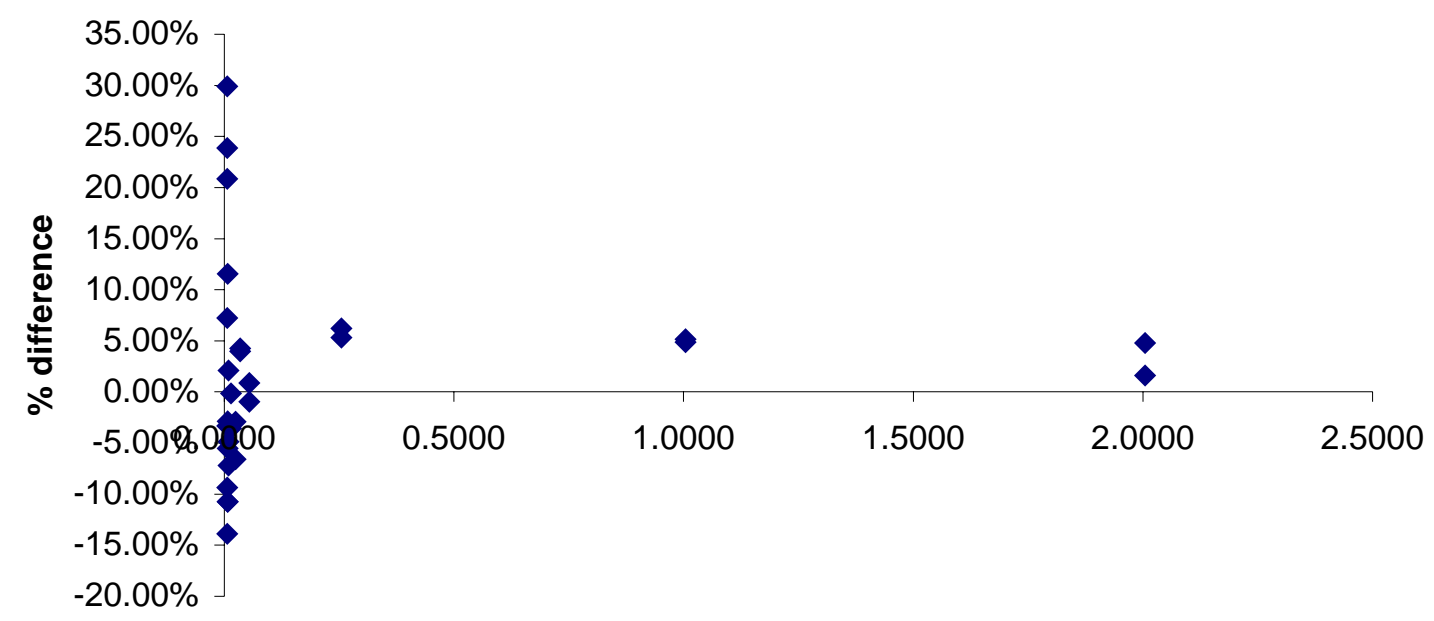

Concentration (ug/l)

Figure 2. Percent error at one standard deviation as a function of the uranium concentration.

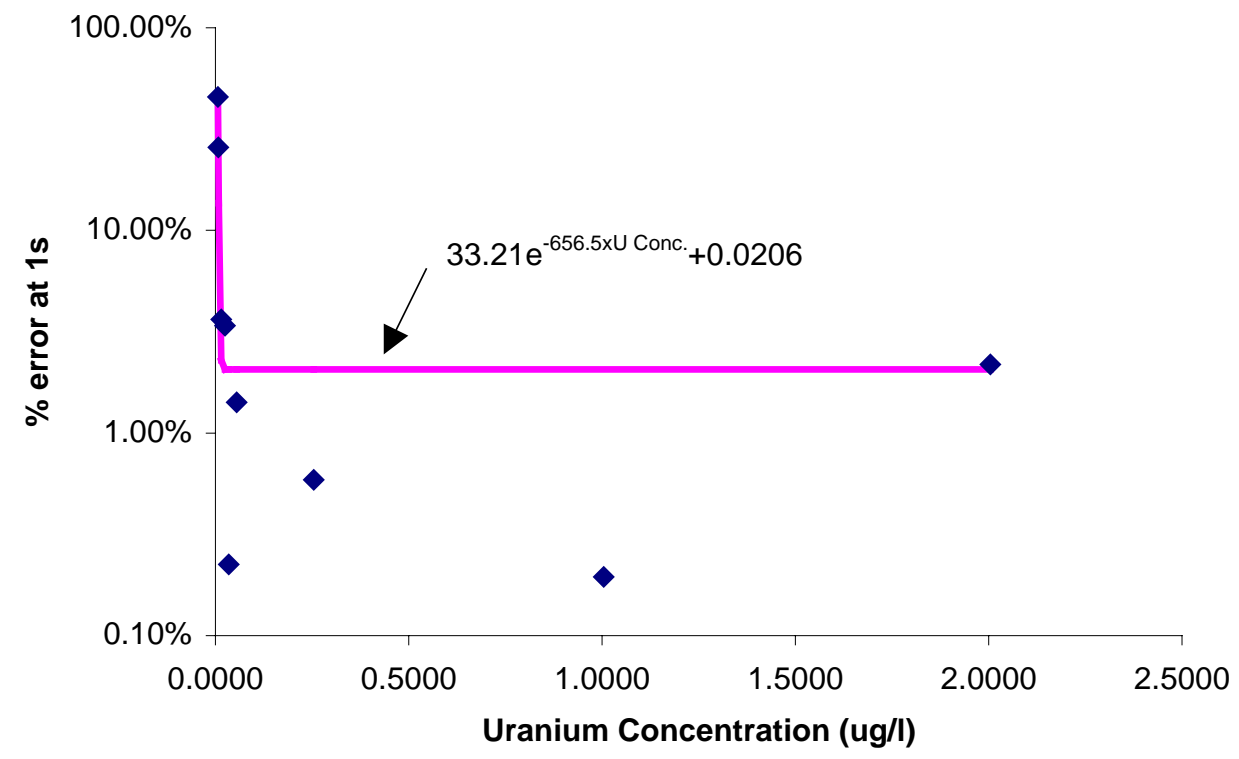




\section{Conclusions:}

A previous evaluation of the errors associated with the ICP/MS analysis of uranium in urine demonstrated a $\pm 9.6 \%$ error in the range of 0.01 to $0.02 \mu \mathrm{g} / \mathrm{l}$. Using the error function derived from this study, this error at $0.01 \mathrm{ug} / \mathrm{l}$ would be $14.5 \%$ and at $0.02 \mathrm{ug} / \mathrm{l}$ would be $4.1 \%$. Thus the errors observed in this study are consistent with the observed errors use in previous evaluations.

Based on the results of this experiment, the observed errors for uranium analysis with amounts ranging from 0.0076 to $2.00 \mu \mathrm{g} / \mathrm{l}$ using the ICPMS is enveloped by the following function:

$$
\pm 1 s(\%)=33.21 \times e^{-656.5 \times u g / l}+0.0206
$$

This error represents the total error associated with the analysis of urine aliquots using the ICP/MS methods developed at LLNL and should be used to propagate the total error of the analysis. 


\section{References}

Snedecor, G.W. and Cochran, W.G., Statistical Methods, $6^{\text {th }}$ Edition, Iowa State University Press, Ames, Iowa, 1967.

SYSTAT for Windows, V6.01, "Statistics", SPSS, 1996. 